\title{
A New Proposal to Guide Velocity and Inclination in the Ramp Protocol for the Treadmill Ergometer
}

\author{
Odwaldo Barbosa e Silva, Dário C. Sobral Filho \\ Recife, PE - Brazil
}

\begin{abstract}
Objective - To suggest criteria to guide protocol prescription in ramp treadmill testing, according to sex and age, based on velocity, inclination, and $\max \mathrm{VO}_{2}$ reached by the population studied.
\end{abstract}

Methods - Prospective study describing heart rate $(\mathrm{HR})$, time, velocity, inclination, and $\mathrm{VO}_{2}$ estimated at maximum effort of 1840 individuals from 4 to 79 years old, who performed a treadmill test (TT) according to the ramp protocol. A paired Student t test was used to assess the difference between predicted and reached max $\mathrm{VO}_{2}$, calculated according to the formulas of the "American College of Sports Medicine".

Results - Submaximal HR was surpassed in $90.1 \%$ of the examinations, with a mean time of 10.0+2.0 minute. Initial and peak inclination velocity of the exercise and max $\mathrm{VO}_{2}$ were inversely proportional to age and were greater in male patients. Predicted $\mathrm{Max}_{\mathrm{VO}}$ was significantly lower than that reached in all patients, except for female children and adolescents (age $<20$ years old).

Conclusion - Use of velocity, inclination, and maximum $\mathrm{VO}_{2}$ actually reached, as a criterion in prescribing the ramp protocol may help in the performance of exercise in treadmill testing. The ramp protocol was well accepted in all age groups and sexes with exercise time within the programmed 8 to 12 minutes.

Key words: treadmill test, exercise tolerance, ramp protocol

Prontocor/Hospital do Coração and Atleticor/Medicina do Exercício.

Mailing address: Odwaldo Barbosa e Silva - Prontocor - Hospital do Coração Rua da Creoulas, 133 - 52011-270 - Recife, PE - E-mail: odwaldo@cardiol.br
Treadmill testing (TT), exercise tolerance or ergometry, is one of the most popular noninvasive methods of diagnosis used in cardiological evaluations. According to American statistics, $8.2 \%$ of patients are advised to undergo the procedure ${ }^{1}$. It is indicated to help diagnoses, establish treatment, determine prognosis, and evaluate functionally the cardiovascular system. Initially, it was used in the investigation of thoracic pain in patients who might have coronary artery disease; later, its use spread to other clinical situations and medical specialties.

Master, in 1929, was the first author to describe a methodology for preforming TT, using the effort to climb 2 stair steps. Cardiac capacity was assessed by the responses of pulse and blood pressure, but the ECG value was not recognized ${ }^{2,3}$. The use of a bicycle ergometer increased after the studies of Astrand et al ${ }^{4}$ in 1954, who established physiological bases for exercise tolerance, correlating oxygen consumption with heart rate to the submaximal level of exercise.

Bruce ${ }^{5}$ introduced the treadmill for performing the test and described the protocol for using this new type of ergometer, marking the beginning of modern methodology for TT. Until the present time, this protocol is the most commonly used and has been standardized by the World Health Organization ${ }^{6}$. In 1959, Balke and Were developed a new exercise protocol and established a formula for the calculation of oxygen consumption based on the velocity and inclination of the treadmill ${ }^{6}$. Ellestad et al ${ }^{7}$ published a TT protocol for treadmill testing with a fixed inclination of $10 \%$ and a velocity of 1.7 miles per hour (mph) for 3 minutes, $3 \mathrm{mph}$ for 2 minutes, $4 \mathrm{mph}$ for 2 minutes, and finally $5 \mathrm{mph}$ for 3 minutes, with a follow-up electrocardiogram (ST and rhythm), and tests for heart rate, blood pressure, and the presence of thoracic pain.

In Brazil, one of the first studies published in the area of ergometry was that of Eugênio do Carmo, of the Instituto Estadual de Cardiologia Aloysio de Castro, in Rio de Janeiro, in 1962. However, the method became known as a routine examination in cardiology thanks to Feher and Magalhães, of the Instituto Dante Pazzanese de Cardiologia de São Paulo ${ }^{6}$. 
In 1981, from the description of the cardiovascular response to ramp testing with an ergometer, this protocol was used in the performance of TT $^{8,9}$. Vivacqua and Hespanha ${ }^{10}$ described special protocols for treadmill testing adapted to the Brazilian population, with the workload applied semiindividually, enabling patients to perform the exercise comfortably and to adjust it to their current physical condition. Myers et al ${ }^{11}$, published the first study comparing other protocols to the ramp protocol, which was the base for further studies using ramp protocols (RP) for the treadmill.

Protocol choice depends on the available ergometer and the patient being assessed. Staggered protocols, such as Bruce, Ellestad, Sheffield and Naughton, commonly used in treadmill tests, recommend workload increases (inclination and velocity) at regular intervals of 2 or 3 minutes ${ }^{10,12,13}$. The intensity of the work remains constant during some minutes and then it is suddenly increased. Patients with different characteristics, such as age, sex, and physical conditioning are submitted to pre-determined workloads of the same intensity, which will cause great variances in examination time according to the characteristics of each individual assessed.

RP is characterized by duration between 8 and 12 minutes, with small and constant increases in the velocity and inclination, individualized for the sex and age of the patient, having as a basis the predicted maximum $\mathrm{VO}_{2}{ }^{9,11,14,15}$ that may be estimated by the formula of the $\mathrm{ACSM}^{14,16}$ [male: $\mathrm{VO}_{2}=1.11 \times(60-0.55 x$ age $)$, female: $\mathrm{VO}_{2}=1.11 x(48-0.37 x$ age $\left.)\right]$ or by the questionnaire "VSAQ" (Veterans Self-Administered Questionnaire $)^{17,18}$. Shorter tests demonstrate smaller values of $\max \mathrm{VO}_{2}$, possibly due to muscular limitation because of greater effort intensity. Likewise, in longer tests, lower $\mathrm{VO}_{2}$ max values were also found, by the increase in body temperature, greater dehydration, muscular discomfort, or by different energetic substratum involved in more prolonged exercises ${ }^{19}$.

Nowadays, the majority of practicing physicians in Brazilian clinics who perform exercise testing use treadmills, and the Bruce protocol is still the protocol of choice. The tendency, however, is to perform RP, which individualizes the increase in workload according to the patient, and enables the performance of TT, regardless of age, sex, or previous physical condition ${ }^{1}$.

Because $\max \mathrm{VO}_{2}$, estimated by formulas, overestimates $\mathrm{VO}_{2}$ when compared with that directly assessed by the cardiopulmonary exercise test ${ }^{20}$, the suggested inclination and velocity by the computerized system, for the performance of ramp exercises, underestimate the duration of the examination. Observing that frequent examinations have times greater than 12 minutes, we started using greater values of inclination and velocity to reach maximum effort, within 8 to 12 minutes.

The present study aims at describing the mean duration of exercise, the velocity, and the inclination reached by patients at peak exercise, distributed by sex and age. $\mathrm{VO}_{2}$ maximum is reached, assessed indirectly with the ACSM ${ }^{14,16}$ formula, and compared with that predicted for the patient.
Thus, we expect to contribute new criteria to guide the prescription of exercise in the performance of RP. We do not intend to perform comparisons of the variables between ages and sexes, because the difference in exercise tolerance after puberty has already been well established ${ }^{21}$.

\section{Methods}

From February 1998 to December 2001, 15,589 tests were performed using the ramp protocol in 3 ergometry laboratories in patients with similar characteristics, having the same health insurance, and sent by the same group of doctors. Of 1,966 examinations performed by one observer, from January 2000 to December 2001, 1,840 were selected with patients' ages between 4 to 79 years, 965 (52.4\%) female and 875 (47.6\%) male.

We included the individuals that concluded the protocols, interrupted due to fatigue, regardless of the diagnosis or the use of medication. We excluded those patients with incomplete data, or with an interrupted protocol due to other causes before exceeding the maximum heart rate (HR max) predicted for the age, calculated by the Karvonen formula ${ }^{22}$. Chest pain, electrocardiographic alterations (ST segment, intraventricular or atrioventricular rhythm and conduction disturbances), abnormal patterns of blood pressure or other abnormalities were some of the other causes interrupting the protocol.

Individuals $<19$ years of age were considered children or adolescents, and those $>60$ years of age were considered elderly.

Variables assessed, represented by mean + standard deviation, categorized by sex and age were velocity and inclination prescribed in the beginning of exercise and reached at maximum effort, duration of exercise, maximum heart rate reached, predicted and reached $\mathrm{VO}_{2}$ maximum at peak effort. Predicted and reached $\mathrm{VO}_{2}$ were assessed by the formula of the American College of Sports Medicine $(A C S M)^{14,16}$ and the statistical analysis used the paired Student $t$ test, with a significance value of $\mathrm{P}<0.05$.

TT were performed using treadmill ergometer Micromed/Inbramed models EM 200 and 10,400, controlled by a computerized system Micromed ErgoPC-13/ErgoPC Elite, which commands the velocity and inclination of the treadmill, estimates $\mathrm{VO}_{2}$ and suggests individualized values for exercise performance. We used a system of electrocardiographic recording of 13 derivations (MC5 and the 12 classic ECG derivations), with placement of electrodes following guidelines of modified Mason and Likar ${ }^{22}$.

In the ramp protocol, the computerized system suggests the velocity and the inclination that the patient must reach at 10 minutes of exercise to reach $\mathrm{VO}_{2}$ determined for sex and age. From the first examinations performed, we observed that the maximum $\mathrm{VO}_{2}$ reached and the exercise time were generally greater than that expected. To perform $\mathrm{RP}$ within the 10 minutes predicted, the values of velocity and inclination started being recommended above those suggested by the computer. For younger patients, the 
parameters were assessed to reach maximum $\mathrm{VO}_{2} 20$ to $30 \%$ above the predicted value and for older patients about $10 \%$. The use of values observed (inclination, velocity, and $\mathrm{VO}_{2}$ maximum reached), started being used as criteria in the protocol prescription.

\section{Results}

Of the 1,840 patients included in the study, with ages between 4 and 79 years $(45.8+16.9), 965$ were women, with a mean age of $48.2+15.6$ and 875 men, with a mean age of $43.1+17.9$ years. More than $75 \%$ of patients were between 30 and 69 years of age, and $192(10.4 \%)$ were children and adolescents. In females, $52 \%$ were between 40 and 59 years old and in males, $58.7 \%$ were between 30 and 59 years old.

In $90.1 \%$, maximum $\mathrm{HR}$ reached was $>$ the predicted submaximal HR for age (efficient test) - female sex $88.8 \%$ and male sex $91.4 \%$. Between children and adolescents, $95.3 \%$ of females and $90.6 \%$ of males performed efficient tests. Elderly patients completed a smaller number of efficient tests $(78.7 \%)$. Average exercise time was $10.0+2.0$ minutes, with 9.5+1.8 minutes for women and 10.6+1.9 minutes for men.

When distributed by sex and age, the mean initial velocity corresponds approximately to half of the maximum velocity reached, and the inclination varies about $10 \%$ between the initial and maximum values, as observed in tables I and II. Mean maximum $\mathrm{VO}_{2}$ reached was greater than that predicted in both sexes and in all age groups. Only female children and adolescents did not have significant differences (tab. III).

\section{Discussion}

The first description of the ramp protocol was published by Myers et al ${ }^{11}$ in 1991, with 44 patients analyzed. One year later, the same authors ${ }^{17}$ studied 200 apparently

\begin{tabular}{|lccc|}
\hline \multicolumn{4}{|c|}{ Table I - Distribution of female patients who performed TT according to the ramp protocol regarding frequency, velocity, and inclination in the beginning } \\
of exercise and at maximum effort (mean standard deviation) - Recife/PE
\end{tabular}

\begin{tabular}{|ccccc|}
\hline \multicolumn{5}{|c|}{ Table II - Distribution of male patients who performed TT according to the ramp protocol regarding frequency, velocity, and inclination in the beginning of } \\
exercise and at maximum effort (mean standard deviation) - Recife/PE
\end{tabular}

\begin{tabular}{|c|c|c|c|c|c|c|c|}
\hline \multicolumn{4}{|c|}{ Female gender } & \multicolumn{4}{|c|}{ Male gender } \\
\hline Age & $\begin{array}{l}\mathrm{VO}_{2} \text { max predicted } \\
\text { Mean SD }\end{array}$ & $\begin{array}{l}\mathrm{VO}_{2} \text { max reached } \\
\text { Mean } \mathrm{SD}\end{array}$ & $\begin{array}{l}\text { t Test } \\
p^{*}\end{array}$ & Age & $\begin{array}{l}\mathrm{VO}_{2} \text { max predicted } \\
\text { Mean SD }\end{array}$ & $\begin{array}{c}\mathrm{VO}_{2} \text { max reached } \\
\text { Mean } \mathrm{SD}\end{array}$ & $\begin{array}{c}\text { Test } t \\
p^{*}\end{array}$ \\
\hline $05 \mid-19$ & $48.1 \pm 1.5$ & $49.8 \pm 7.9$ & 0.11 & $04-19$ & $58.3 \pm 2.2$ & $60.9 \pm 12.8$ & 0.031 \\
\hline $20 \mid-29$ & $42.5 \pm 1.2$ & $47.9 \pm 9$ & $<0.001$ & $20 \mid-29$ & $50.5 \pm 1.6$ & $54.9 \pm 10.9$ & 0.001 \\
\hline $30-39$ & $38.4 \pm 1.2$ & $44 \pm 8.6$ & $<0.001$ & $30-39$ & $44.8 \pm 1.7$ & $54.4 \pm 11.8$ & 0.000 \\
\hline $40 \mid-49$ & $34.5 \pm 1.1$ & $40.9 \pm 7.2$ & $<0.001$ & $40 \_-49$ & $39.1 \pm 1.8$ & $51.8 \pm 10.5$ & 0.000 \\
\hline $50-59$ & $30.8 \pm 1.2$ & $37.6 \pm 7.6$ & $<0.001$ & $50-59$ & $33.2 \pm 1.8$ & $46.3 \pm 9.2$ & 0.000 \\
\hline $60 \mid-69$ & $26.6 \pm 1.2$ & $31.4 \pm 7.2$ & $<0.001$ & $60 \mid-69$ & $27.2 \pm 1.6$ & $40.3 \pm 8.3$ & 0.000 \\
\hline $70 \mid-79$ & $23.1 \pm 1.1$ & $25.5 \pm 6.9$ & 0.008 & 70 & $21.7 \pm 1.4$ & $32.1 \pm 8.3$ & 0.000 \\
\hline
\end{tabular}


healthy patients. Aksut et al ${ }^{23}$ assessed hemodynamic responses in 30 young healthy patients ( 11 men and 19 women), comparing the Bruce protocol with a customized ramped protocol. In the same year, Yokoyama et al ${ }^{24}$, also compared the response between these 2 protocols in 17 men and 5 women. A more significant number, of 698 patients from both sexes, was analyzed by Kaminsky and Whaley ${ }^{25}$, with the ramped Bruce protocol. Bader et $\mathrm{al}^{26}$ observed the pattern of 24 individuals with age $>60$ years participating in the ramp protocol and McInnis et al ${ }^{27}$, in 25 obese women. In the same year, Will and Walter ${ }^{28}$ compared the Bruce protocol with the ramped Bruce protocol in 23 patients.

Therefore, we observed that the numbers of patients assessed in the present study was greater than that of the several prospective studies published on the ramped protocol. We did not consider the use of medications or the association between diseases in this population, because the main variables assessed were duration of exercise, the velocity and the inclination reached, and the $\max \mathrm{VO}_{2}$ assessed in relation to the predicted value (by the formula of $\mathrm{ACSM}^{16}$ ). In $90.1 \%$ of the patients, the max HR reached was $>85 \%$ of the maximum HR predicted by the Karvonen formula ${ }^{22}$. Only the patients with age $>$ to 60 years old, in frequent use of medications that could interfere the chronotropism, had a relative frequency of ineffective examinations $<80 \%$. This population of elderly patients reached on average $91.4+11.9 \%$ of the predicted maximum HR, compared with $83+10 \%$ of the patients studied by Bader et al ${ }^{26}$ in 1999. In the age group 20 to 39 years, almost $100 \%$ of the individuals reached the predicted submaximal HR.

Mean exercise duration was $10+2$ minutes, regardless of age and sex, and was within the time of 8 to 12 minutes, according to that suggested by the latest guidelines of the ACC/AHA ${ }^{29}$ in 1997 and of ACSM ${ }^{30}$ in 2000 and also according to the publications that describe the methodology and the interpretation of TT and that states that the optimal duration of exercise must be between 8 and 12 minutes $8,9,11,15,17,18,31$. The computer programs developed to customize the test aimed at reaching predicted maximum $\mathrm{VO}_{2}$ within this ideal time ${ }^{11,32}$. The exercise period in the Bruce protocol is significantly lower than those of Balke and ramp, and the protocols with shorter periods cause greater discrepancies between $\mathrm{VO}_{2}$ and workload ${ }^{11}$. Tests longer than 15 minutes may become monotonous for healthy individuals or those with heart diseases, in addition to involving a suitable evaluation of oxygen uptake. The time of exercise and the suitability to hemodynamic conditions make the test more pleasant, safer, and more accurate ${ }^{18}$. Review of the literature by Myers and Bellin ${ }^{8}$ reinforces previous statements that in ramped TT the exercise must be customized, to reach predicted maximum $\mathrm{VO}_{2}$ in 9 to 10 minutes.

In the present study, only the female patients with ages below 20 years old did not have significant differences when compared with the predicted value and reached values of maximum $\mathrm{VO}_{2}$, calculated according to the ACSM formula, according to sex and age group. In the other patients, regardless of sex and age, the oxygen uptake reached was significantly greater than that predicted, in accordance with Araújo ${ }^{20}$ where $\mathrm{VO}_{2}$ estimated by formulas overestimates $\mathrm{VO}_{2}$ when compared with that measured through the analysis of expired gases. Mean values of velocity and inclination, reached at maximum effort, were greater than those estimated at the prescription of customized ramp, using predicted maximum $\mathrm{VO}_{2}$ as the pattern.

Myers et al ${ }^{11}$, in 1991, published the first study that compared other protocols to those of ramp. Forty-one patients were submitted to 6 different protocols, 3 with a treadmill ergometer (Bruce, Balke, and ramp) and 3 with a cycle ergometer ( 25 watts, 50 watts per stage, and ramp). They observed hemodynamic responses and gas exchanges and developed computer programs to customize the ramp protocol, based on the capacity of exercise on a treadmill and bicycle, to obtain an optimal exercise duration of 9 to 10 minutes. $\mathrm{Max} \mathrm{VO}_{2}$ for the treadmill was $16 \%$ greater with the cycle ergometer. There was no significant difference in heart rate, blood pressure, or maximum $\mathrm{VO}_{2}$ between the treadmill and cycle ergometer protocols (using the same ergometer). In all protocols with or without ramp, predicted maximum $\mathrm{VO}_{2}$ was greater than that measured. The error in predicting $\mathrm{VO}_{2}$ by the workload was lower with the ramp protocol, which presents a more linear correlation between these parameters. Using protocols with short and small workload increases between the stages or using the ramp protocol, maximum $\mathrm{VO}_{2}$ reached through the analysis of gases exhaled had closer levels of predicted maximum $\mathrm{VO}_{2}$.

Myers et al ${ }^{17}$ stated that the protocol choice may might influence the assessment of variables. The causes of interruption ( $\mathrm{ST}$ segment, $\mathrm{HR}$, and $\mathrm{VO}_{2}$ ) may vary according to the protocol. Customization of the test, with reduced workload increase and adequate duration ( 8 to 12 minutes) are recommendations to enhance the test. Yamamoto et al ${ }^{33}$ developed a computer program to control the increase in velocity and inclination of the treadmill ergometer to enable a linear increase in $\mathrm{VO}_{2}$ with the individual walking until the end of the exercise, according to the duration of the examination.

For Myers and Froelisher ${ }^{31}$, the exercise protocol must be customized, with small and constant progressive increases in inclination and velocity, to perform the test in 8 to 12 minutes. Comparison of results between different examinations may be done through the workload rather than exercise duration, such as with the Bruce protocol.

Fletcher et al ${ }^{32}$ observed the disadvantages of the Bruce protocol: a sizable increase in workload between stages; in the 4th stage the patient can walk or run, which leads to differences in $\mathrm{VO}_{2}$ determination; the test may be interrupted due to discomfort in inferior limbs or the inability to tolerate great increases in workload with changes in stage. They concluded that the ramp protocol, customized for the patient tested, with low workload increases and a shorter time interval and with 9-minute duration, demonstrates greater accuracy in the maximum $\mathrm{O}_{2}$ reached.

Mastrocolla et al ${ }^{22}$, of the Consenso Nacional de Ergometria, do Departamento de Ergometria e Reabilitação Car- 
diovascular da Sociedade Brasileira de Cardiologia, comment that, recently, greater clinical interest has been shown in exercise testing protocols that meet the characteristics of linearity in the responses of oxygen uptake. These protocols, generally known as ramp protocols, use a constant increase ratio for exercise intensity rather than the stages of definite duration, enabling a greater customization and adaptation of the protocol to the patients' condition, and being able to be performed both on cycle and treadmill ergometers.

Aksut et $\mathrm{al}^{23}$ compared the Bruce protocol with a customized ramp protocol in healthy men and women. They did not observe significant differences between the protocols regarding heart rate, blood pressure, ventricular function, or measured $\mathrm{VO}_{2}$.

Another methodology of exercise testing with continuous protocols of increasing load was used by Mahseredjian et $\mathrm{l}^{34}$, in a comparative study of methods (treadmill test with direct $\mathrm{VO}_{2}$ measure and field test with indirect $\mathrm{VO}_{2}$ determination) to predict maximum oxygen uptake and anaerobic thresholds in athletes: initial velocity of $9 \mathrm{~km} / \mathrm{h}$ with increase an of $1 \mathrm{~km} / \mathrm{h}$ per minute up to $15 \mathrm{~km} / \mathrm{h}$ and, after that, an increase in inclination of $5 \%$ per minute until exhaustion. $\mathrm{VO}_{2}$ max determined by the direct method was not correlated to that determined by the lane test.

For Vivacqua ${ }^{35}$, the ramp protocol, with a progressive workload has enabled determining more precisely the ischemic threshold in stratification of patients with chest pain in tests performed in most cases, between 12 and 24 hours after emergency admittance. According to this author, ramp protocols enable better adaptation to the ergometer, with greater performance during exercise, greater reliance in the determination of electrocardiographic, and hemodynamic variables, of the oxygen uptake at peak effort, and of the ventilatory threshold. The exercise duration and the suitability to biomechanical conditions of the individuals make the test more pleasant, safer, and more accurate.

McInnis et al ${ }^{27}$ studied 25 obese women to compare the values of predicted maximum oxygen uptake with that determined by direct measurement, using 2 exercise protocols with the treadmill ergometer: Bruce protocol and a cus- tomized ramp protocol. The result of this study suggests that the ramp and staggered protocols have similar capacity in the assessment of functional capacity in obese women.

Will and Walter ${ }^{28}$ studied hemodynamic responses, test duration, and patient comfort with the conventional Bruce protocol and a ramp Bruce protocol. No significant differences occurred in values for heart rate, blood pressure, and subjective evaluation of noticed effort (Borg scale) at the end of exercise. Duration of exercise and maximum $\mathrm{VO}_{2}$ were significantly greater, and the patients reported greater facility and comfort with the ramp Bruce protocol.

The American College of Sports Medicine ${ }^{30}$ recommends that "whatever the chosen protocol, it must be customized, with velocity (if treadmill) based on the individual capacity and workload increase so that the test lasts 8 to 12 minutes." Historically, the protocol for exercise was based on tradition, convenience, or both. As of the 1990s, studies have suggested that protocols with different and greater workload increases do not maintain a linear correlation between $\mathrm{VO}_{2}$ and the work performed, with an overestimated predicted $\mathrm{VO}_{2}{ }^{8}$. The ramp protocol is close to the guidelines of policies that propose a customized protocol for each patient ${ }^{29}$.

The current tendency is to use customized ramp protocols, with an increase in effort intensity according to the patient, so that the test duration remains between 8 and 12 minutes, which facilitates the analysis of hemodynamic and ventilatory variable patterns ${ }^{1}$.

In conclusion, despite the use of velocity, inclination, and maximum effort variations above that predicted by the computerized system, the ramp protocol was well tolerated by patients, regardless of age, sex, use of medication or preexisting diseases, with a mean exercise duration of $10.0+2.0$ minutes, within the suggested limit by several authors. The use of inclination and velocity, effectively reached by the patients, distributed according to sex and age may be used as one more criterion to guide parameters for the performance of the ramp protocol with a treadmill ergometer. The use of calculated $\mathrm{VO}_{2}$ maximum, significantly greater than the predicted $\mathrm{VO}_{2}$ for almost all patients from both sexes can also be useful to prescribe velocity and inclination of the customized ramp protocol.

\section{References}

1. Araújo CGS. Teste de exercício: terminologia e algumas considerações sobre passado, presente e futuro baseado em evidências. Rev Bras Med Esporte 2000; 6: 77-84.

2. Alfieri RG, Marcondes GD. Histórico. In: Exercício e o Coração. $2^{\mathrm{a}}$ ed. Rio de Janeiro: Cultura Médica, 1993: 3-9.

3. Ellestad MH. História do teste de esforço. In: Prova de Esforço. $2^{\mathrm{a}}$ ed. Rio de Janeiro: Cultura Médica, 1984: 2-5.

4. Ästrand PO, Rodahl K. Avaliação da capacidade de trabalho físico na base dos testes. In: Tratado de Fisiologia do Exercício. $2^{\mathrm{a}}$ ed. Rio de Janeiro: Interamericana, 1977: 304-36.

5. Bruce RA. Evaluation of functional capacity and exercise tolerance of cardiac patients. Mod Concepts Cardiovasc Dis 1956; 25: 321-6.

6. Vivacqua R, Hespanha R. Introdução-Histórico-Perspectiva. In: Ergometria e Reabilitação em Cardiologia. Rio de Janeiro: Medsi, 1992: 1-6.
7. Ellestad MH, Allen W, Wan MCK, Kemp G. Maximal treadmill stress testing for cardiovascular evaluation. Circulation 1969; 39: 517-22.

8. Myers J, Bellin D. Ramp exercise protocol for clinical and cardiopulmonary exercise testing. Sports Med 2000; 30: 23-9.

9. Serra S. Considerações sobre ergoespirometria. Arq Bra Cardiol 1997; 68: 301-4.

10. Vivacqua R, Hespanha R. Metodologia do teste ergométrico. In: Ergometria e Reabilitação em Cardiologia. Rio de Janeiro: Medsi, 1992: 39-100.

11. Myers J, Buchanan N, Walsh D, et al. Comparison of the ramp versus standard exercise protocols. J Am Coll Cardiol 1991; 17: 1334-42.

12. Ellestad MH. Protocolo do teste de esforço. In: Prova de Esforço. $2^{\mathrm{a}}$ ed. Rio de Janeiro: Cultura Médica, 1984: 105-126.

13. Alfieri RG, Marcondes GD. Metodologia. In: Exercício e o Coração. $2^{\mathrm{a}}$ ed. Rio de Janeiro: Cultura Médica, 1993: 47-72. 
14. Protocolo em rampa: manual de referência rápida. Brasília, 1998. Disponível em: URL: http://www.micromed.ind.br/ergopc13/download/rampa.pdf. Acesso em 28/2/01.

15. Dubach P, Litscher K, Ratti R, Reinhart WH. Current aspects in ergometry. Schweiz Med Wochenshr 1993; 123: 214-22.

16. American College of Sports Medicine. Cálculos metabólicos. In: Manual para o Teste de Esforço e Prescrição do Exercício. $5^{\mathrm{a}}$ ed. Rio de Janeiro: Revinter, 2000: 237-50

17. Myers J, Buchanan N, Smith D, et al. Individualized ramp treadmill. Observations on a new protocol. Chest 1992; 101(Suppl 5): 236-41

18. Vivacqua R. Considerações sobre o protocolo de rampa aplicado no teste ergométrico. Boletim do Departamento de Ergometria e Reabilitação Cardiovascular da SBC 1999; 18: 16-7.

19. Barros Neto TL, César MC, Tambeiro VL. Avaliação da aptidão cardiorrespiratória. In: Ghorayeb N, Barros Neto T. O Exercício: Preparação Fisiológica, Avaliação Médica, Aspectos Especiais e Preventivos. São Paulo: Atheneu, 1999: 15-24.

20. Araújo CGS. A Ergoespirometria como procedimento em medicina do exercício: necessidade, opção ou luxo? Jornal de Medicina do Exercício 1998; 20: 4-5.

21. Ästrand PO, Rodahl K. Capacidade para o trabalho físico. In: Tratado de Fisiologia do Exercício. $2^{\mathrm{a}}$ ed. Rio de Janeiro: Interamericana, 1977: 265-303.

22. Mastrocolla LE, Brito AX, Brito FS, et al. Consenso Nacional de Ergometria. Arq Bras Cardiol 1995; 65: 189-211.

23. Aksut SV, Pancholy S, Johnson J, et al. Comparison of left ventricular performance in healthy young women and men during exercise. J Nucl Cardiol 1996; 3:415-21.

24. Yokoyama Y, Tanabe K, Yamamoto A, et al. Relationship between ischemic ST depression and uptake kinetics during ramp exercise test in patients with effort angina. J Cardiol 1996; 27: 241-6.
25. Kaminsky LA, Whaley MH. Evaluation of a new standardized ramp protocol: the BSU/Bruce Ramp protocol. J Cardiopulm Rehabil 1998; 18: 438-44.

26. Bader DS, Maguire TE, Balady GJ. Comparison of ramp versus step protocol fo exercise testing in patients $\geq 60$ years of age. Am J Cardiol 1999; 83: 11-4.

27. McInnis KJ, Bader DS, Pierce GL, Balady GJ. Comparison of cardiopulmonary responses in obese women using ramp versus step treadmill protocols. Am J Cardiol 1999; 83: 289-91.

28. Will PM, Walter JD. Exercise testing: improving performance with a ramped Bruce protocol. Am Heart J 1999; 138: 1033-7.

29. ACC/AHA Guidelines for Exercise Testing: A Report of the American College of Cardiology/American Heart Association Task Force on Practice Guidelines (Committee on Exercise Testing). J Am Coll Cardiol Data???? 30: 260-315.

30. American College of Sports Medicine. Avaliação clínica em esforço. In: Manual para o Teste de Esforço e Prescrição do Exercício. $5^{\mathrm{a}}$ ed. Rio de Janeiro: Revinter, 2000: 77-96.

31. Myers J, Froelisher VF. Exercise testing. Procedures and implementation. Cardiol Clin 1993; 11: 199-213.

32. Fletcher GF, Balady C, Froelicher VF, Hartley LH, Haskell WL, Pollock ML Exercise standards. A statement for healthcare professionals from the American Heart Association. Circulation 1995; 91: 580-615.

33. Yamamoto M, Tanabe K, Ohmiya K, et al. Development of computer software in ramp slope controlles for treadmill ergometer. J Cardiol 1992; 22: 687-93.

34. Mahseredjian F, Barros Neto TL, Tebexreni AS. Estudo comparativo de métodos para a predição do consumo máximo de oxigênio e limiar anaeróbio em atletas. Rev Bras Med Esporte 1999; 5: 167-72.

35. Vivacqua R. Importância do teste ergométrico na estratificação de pacientes com dor torácica na emergência hospitalar. Boletim do Departamento de Ergometria Reabilitação Cardiovascular da SBC 1999; 16: 14-5. 